\title{
Proizvodnja kamilice (Matricaria chamomilla L.) kao poduzetnička prilika
}

\section{Sažetak}

Kamilica (Matricaria chamomilla L.) je vrlo rasprostranjena biljna vrsta jer uspijeva na različitim tipovima tala što je čini interesantnom kulturom za intenzivnu proizvodnju. Rast potražnje za ljekovitim biljem pa tako i za kamilicom inicira poduzetničke ideje koje treba provjeriti postupcima analize tržišta, tehničke opremljenosti, agrotehnike i ekonomske opravdanosti poslovnog pothvata. Ciljevi rada su prepoznati značenje primjene poduzetništva u proizvodnji kamilice, prikazati cijene inputa i outputa na tržištu, utvrditi tehnološke postupke za očekivane proizvodne rezultate i ekonomsku opravdanost. U radu se determiniraju i primjenjuju analitički postupci neophodni za utvrđivanje ekonomske opravdanosti proizvodnje kamilice kao poduzetničke prilike. Prvi dio rada sadrži opis agrotehnike koja je neophodna za postizanje očekivanih prinosa u proizvodnji kamilice. Utvrđeno je kako kamilica dobro podnosi sušu, uspijeva na vrlo siromašnim tlima, obogaćuje tlo humusom, popravlja strukturu tla, ne zahtijeva zaštitna sredstva niti posebne pretkulture. Drugi dio rada čine analitički postupci provjere poduzetničke ideje kako bi proizvodnja kamilice zaista i postala poduzetnička prilika. Rezultati analiza potvrđuju ekonomičnu $(1,31)$ i rentabilnu $(23,72 \%)$ proizvodnju. Uz relativno niske investicije postiže se pozitivan financijski rezultat te je proizvodnja kamilice profitabilna (31,09\%). Planiranjem i analizom poduzetnici stječu cjelovitu informacijsku osnovu za postizanje ekonomske uspješnosti poslovnog pothvata.

Ključne riječi: kamilica, ekonomika proizvodnje, poduzetništvo

\section{Uvod}

Poduzetnička aktivnost katalizator je gospodarskih promjena neophodnih za razvoj nacionalnog gospodarstva. Poduzetnici u poljoprivredi subjekti su poduzetničke aktivnosti, a o njihovoj brojnosti i ekonomskoj snazi izravno ovisi i razvoj poljoprivrede. U uvjetima poslovnog okruženja i brzog pristupa informacijama, primjenom suvremenih tehnologija proizvodnje i sustava potpore poduzetništvu kakav ima Hrvatska, poduzetnici mogu brže i lakše prepoznati poslovne prilike te ih koristiti za uspješnije razvojno orijentirano poslovanje.

Značenje primjene poduzetništva u poljoprivredi povezano je s proizvodnjom novih proizvoda, primjenom novih tehnologija te uvođenjem nepoljoprivrednih dopunskih aktivnosti u gospodarske subjekte. Primjena inovativnosti, inventivnosti i kreativnosti u vrstama proizvoda i tehnologijama često nije povezana s visokim kapitalnim ulaganjima niti s višegodišnjim aktivnostima koje je potrebno strpljivo i uporno provoditi kako bi se postigli očekivani rezultati. Poduzetničke ideje moguće je koncipirati i na osnovu starih/novih proizvoda koji u prošlom razdoblju nisu bili dovoljno prepoznati ili vrednovani. Kako bi ideja postala poduzetnička prilika u proizvodnji kamilice neophodno je pronaći kvalitetno tržište potražnje zbog otkupnih količina i cijena - output, ali i tržište ponude zbog kvalitetnih inputa, mogućnosti nabave potrebnih količina i prihvatljivih nabavnih cijena. 
Poljoprivredna proizvodnja je izvor sirovina za prerađivačku industriju pa se tako kamilica proizvodi za potrebe farmaceutske i prehrambene industrije. Ona se najviše koristi kao sirovina za proizvodnju čajeva i eteričnih ulja. Pri sušenju kamilice u sušarama se kao gorivo koristi biomasa koja je jeftinija i ekološki prihvatljivija u odnosu na ulje i plin.

Proizvodnja kamilice je oblik nekonvencionalne proizvodnje i netradicionalnih proizvoda. Tradicionalni pristup pri izboru proizvodne orijentacije poljoprivrednika neophodno je prilagoditi tržišno orijentiranom gospodarstvu. Prema tradicionalnom pristupu dugoročni, strateški cilj bio je osiguranje stabilnosti, što je i danas praksa velikog broja hrvatskih poljoprivrednika proizvodnjom konvencionalnih i tradicionalnih proizvoda. Međutim, u dinamičnim uvjetima tržišnog okruženja potrebno je pratiti tržište i upravljati promjenama na poljoprivrednom gospodarstvu.

Prepoznavanje proizvodnje kamilice kao poduzetničke prilike za razvoj poslovanja poljoprivrednog gospodarstva predstavlja izazov poduzetnicima. Kako bi poduzetnicima u poljoprivredi ovakav izazov ostvario očekivanu uspješnost, cilj rada je determinacija i primjena analitičkih postupaka poslovnog planiranja neophodnih za ekonomski opravdanu proizvodnju kamilice.

\section{Materijali i metode}

Pri izradi rada korišteni su podaci iz znanstvene i stručne literature o tehnologiji uzgoja kamilice te ekonomike proizvodnje. Rezultati se temelje na metodama planske kalkulacije $\mathbf{i}$ izračunima apsolutnih i relativnih ekonomskih pokazatelja učinkovitosti proizvodnje.

Načinjena je analiza nabavnog i prodajnog tržišta, analiza strukture troškova i prihoda. Temeljem metoda analize, sinteze i komparacije dobivenih rezultata sačinjena je zaključna ocjena ekonomske opravdanosti proizvodnje kamilice. Rezultati istraživanja su prikazani tablično i grafički.

\section{Rezultati i rasprava}

Agrotehnika proizvodnje

Matricaria chamomilla L. znanstveni je naziv za kamilicu, aromatičnu biljku podrijetlom sa Sredozemlja, koja se proširila po cijeloj Europi. Rod Matricaria pripada porodici glavočika, Asteraceae. Kamilica je jednogodišnja biljka koja uspijeva na siromašnim i bogatim tlima. Od kamilice se koristi suhi cvijet (Chamomilla flos) i destilacijom izdvojeno eterično ulje (Chamomilla aetheroleum). Od cvijeta kamilice prave se čajevi, kupelji i tinkture. Uporaba kamilice ima dugu tradiciju zbog djelovanja protiv svih vrsta upala te su ljudi bolje upoznati s ljekovitim svojstvima kamilice u odnosu na drugo ljekovito bilje. Cvijet kamilice je ugodnog mirisa i aromatičnog okusa. U Hrvatskoj su poznate dvije tetraploidne i jedna diploidna sorta kamilice. Za proizvodnju se preporučuje tetraploidna sorta, zbog ujednačene morfologije, većeg prinosa cvijeta i eteričnog ulja, u odnosu na diploidnu sortu (Parađiković, 2014).

Agroekološki uvjeti su izuzetno važni za tvorbu maksimalne količine eteričnog ulja u cvijetu kamilice. Minimalna temperatura za nicanje i rast je $6^{\circ} \mathrm{C}$, a optimalna temperatura za rast i razvoj je 20 do $25^{\circ} \mathrm{C}$. Pri temperaturama nižim od $20^{\circ} \mathrm{C}$ u stadiju oblikovanja cvjetnih glavica smanjuje se udio eteričnog ulja. Klijanci ugibaju pri temperaturama ispod $0^{\circ} \mathrm{C}$, ali kamilica je inače vrlo otporna na zimske hladnoće. Kada uđe u zimu u fazi rozete (nakon nicanja, a prije busanja), može podnijeti mraz od $-30^{\circ} \mathrm{C}$. Zbog toga, kao i zbog većih prinosa, kamilica se sije $u$ jesenskom sjetvenom roku, a pritom se nastoji da se ulazak u zimu poklapa s ulaskom biljke $u$ fazu rozete. Kamilica dobro podnosi sušu, ne zahtijeva mnogo svjetlosti i uspijeva na gotovo svim tipovima tla (Ekopoduzetnik, 2012).

Plodored je bitna stavka pri tehnologiji proizvodnje kamilice, iako kamilica ne zahtijeva po- 
sebnu pretkulturu. Za dobar urod i prihvatljivu kvalitetu kamilice potrebno je isplanirati takav plodored da se pretkultura uklanja s tla do kolovoza, jer se tlo za sjetvu treba pripremiti krajem kolovoza. Uljana repica se smatra lošom pretkulturom jer u kamilici niče i nekoliko godina poslije. Bitno je da je parcela što manje zakorovljena te da se korov nije pretjerano pojavljivao u pretkulturi. Kamilici ponajviše smeta višegodišnji širokolisni korov, a ako se pojavi, potrebno je promijeniti sjetvenu površinu. Kamilica se može uzgajati i u monokulturi, ali ne duže od tri godine. Upotreba herbicida u pretkulturi negativno utječe na kamilicu. Ona je dobra pretkultura jer obogaćuje tlo humusom te popravlja strukturu tla. Uporabom herbicida se suzbija rast i razvoj kamilice u naknadno zasijanim ratarskim kulturama, znači sjeme kamilice ne zagađuje proizvodne površine (Šilješ i sur., 1992).

Njega usjeva u ekološko prihvatljivoj proizvodnji kamilice je vrlo zahtjevna. Zaštita kamilice se ne oslanja na samo jednu metodu već na zajedničko djelovanje više njih. Potreban je odabir kvalitetnog sjemena jer čistoća sjemena utječe na rast korova u usjevu. Pravilna obrada tla i oranje uništavaju korov prije sjetve dok pravilan plodored smanjuje zakorovljenost i sprječava pojavu štetnika. Gnojidba dušikom u proljeće potiče rast kamilice u odnosu na korov. Uništavanje korova obavlja se ručno pri čemu se uništavaju samo krupniji korovi sredinom travnja (Ecofoodtura, 2016).

Prema Sito i sur. (2015) berba kamilice je u svibnju i početkom lipnja. Berba se određuje prema stanju cvijeta, ako je $70 \%$ cvjetnih glavica fiziološki zrelo, berba može započeti.

Nakon rane prve berbe, potrebna je kiša u roku od par dana ili navodnjavanje, kako bi nastali uvjeti za drugu berbu. Druga berba je za oko 2 tjedna, kojom se dobiva do $50 \%$ prinosa prve berbe. Kada prva berba nije na vrijeme, nastaju veliki gubici jer se prvi procvali cvjetovi počinju osipati. Berba se obavlja preuređenim žitnim kombajnom. Potrebno je oko tri sata za berbu jednog hektara usjeva kamilice koji nije polegao. Prinos varira od 3 do 6 tona svježeg cvijeta kamilice, ovisno o agroekološkim uvjetima. Prosječan prinos je 4 tone po hektaru svježeg cvijeta, s $60 \%$ cvijeta prve klase, dok prinos eteričnog ulja može varirati od 0,3 do 0,5 kilograma po hektaru (Europlantaže, 2015).

\section{Analiza tržišta nabave i prodaje}

U suvremenim uvjetima brzih i dinamičnih promjena, uloga istraživanja tržišta postaje sve važnija jer pruža poduzetnicima uvid u tržišne činjenice i smanjuje poslovni rizik. Svaka poslovna odluka temelji se na informacijama prikupljenim analizom. Istraživanje tržišta je standardizirani postupak zasnovan na principima znanstvenih metoda kojim se prikupljaju, analiziraju i interpretiraju podaci sa svrhom dobivanja informacija potrebnih u odlučivanju i rješavanju problema na području tržišnog poslovanja (Tolušić, 2011).

Prema Žanić (2000) planiranje nabave mora odgovoriti na nekoliko pitanja: što će se nabavljati, po kojoj cijeni (cijena sirovine direktno utječe na kvalitetu i cijenu finalnog proizvoda), od kojeg dobavljača, koji su rokovi isporuke, kakvi su uvjeti plaćanja te koliki su troškovi nabave (prijevoz, carina, osiguranje).

Tržište prodaje je najvažniji dio postupka poduzetničkog poslovnog planiranja jer treba prikupiti informacije o tome što će se proizvoditi i po kojoj cijeni, na kojem tržištu te koji su ciljni kupci (Centar za poduzetništvo, 2004).

Za proizvodnju kamilice potrebna je sjemenska smjesa po nabavnoj cijeni od 22,00 kune po kilogramu (Spidergrupa, 2018). Za jedan hektar je potrebno 12 kilograma sjemenske smjese što ukupno iznosi 264,00 kuna. Ishrana kamilice ovisi o plodnosti tla i o izgledu samog usjeva. Koristi se $150 \mathrm{~kg} \mathrm{ha}^{-1}$ NPK 15:15:15 po cijeni od 585,00 kuna, $150 \mathrm{~kg} \mathrm{ha}^{-1}$ NPK 7:20:30 po cijeni od 735,00 kuna i $70 \mathrm{~kg} \mathrm{ha}^{-1} \mathrm{KAN}-\mathrm{a}$ po cijeni od 203,00 kune. Reprodukcijski materijal potrebno je nabaviti po tržišnim cijenama u potrebnim količinama i uz standardnu kvalitetu (Petrokemija, 2018). 
Pri intenzivnoj proizvodnji na većoj površini potrebna je odgovarajuća mehanizacija. Za takvu proizvodnju potreban je traktor jačine $50 \mathrm{KS}$, procijenjene vrijednosti $80.000,00 \mathrm{kuna}$. Za kupovinu dvobraznog pluga s crtalom i točkom potrebno je izdvojiti 4.650,00 kuna procijenjene vrijednosti. Cijena rasipača za gnojivo veličine koša 600 kilograma, procijenjene vrijednosti je 6.000,00 kuna. Sijačica za kamilicu s valjkom, procijenjene cijene je 9.700,00 kuna. Tanjurača je procijenjene vrijednosti 11.000,00 kuna. Kada se kamilica proizvodi na većoj površini, potrebno je uložiti minimalno 111.350,00 kuna u dugotrajnu materijalnu imovinu, bez kombajna koji nije isplativ za kupnju na manjim površinama.

Pri proizvodnji kamilice na jednom hektaru, svu potrebnu mehanizaciju preporučljivo je unajmiti. Preuređeni žitni kombajn se unajmljuje po cijeni od 233,33 kune po satu rada, a traktor po cijeni od 148,00 kuna po satu rada.

Potrebna je kontinuirana sušara, koja je ekonomski i ekološki prihvatljivija od izvedbe koja koristi plin ili loživo ulje. Prosječni kapacitet takvih izvedbi sušara je najčešće oko 2.000 kg svježe kamilice. Troškovi sušenja su 1.625,00 kuna po toni.

Proizvedena količina suhe kamilice prodaje se po otkupnoj cijeni od 9,00 do 15,00 kuna po kilogramu.

Pravilno provedeni tehnološki postupci preduvjet su postizanja proizvodnih rezultata koji su izraženi masom prinosa po hektaru proizvodne površine. Nakon analize tržišta nabave i prodaje moguće je provesti ekonomsku analizu proizvodnje.

Ekonomska analiza proizvodnje kamilice kao poduzetničke poslovne prilike

Vrijednost poslovne prilike mjeri se količinom moguće prodaje proizvoda, ali i mogućnošću nabavke sirovina odgovarajuće kvalitete, količine i cijene. Prodajno tržište je izvor prihoda, a nabavno izvor troškova. Poznavanje terminologije i odnosa pojedinih dijelova poslovnog ciklusa u analizi tržišta je polazište u praktičnoj razradi i proračunu prihodne i rashodne strane (Deže i sur., 2008).

Ekonomika proizvodnje izučava ekonomske probleme određenih proizvodnih sustava, istražuje čimbenike koji utječu na njihovu uspješnost i spoznaje zakonitosti u odnosima proizvodnih sustava, njihovih dijelova i utjecajnih čimbenika. Zadaća ekonomike je pružanje znanja za uspješno poslovanje poduzeća (Juračak, 2005).

Uspješnost poslovanja gospodarskih subjekata u poljoprivrednoj djelatnosti može se mjeriti apsolutnim i relativnim veličinama. Prema Ranogajec (2009) najvažnija apsolutna mjerila su: vrijednost proizvodnje, ukupni troškovi i ostvareni financijski rezultat, dok se relativni pokazatelji najčešće izražavaju kao ekonomičnost, rentabilnost i produktivnost.

Pri planiranju realizacije i vrednovanju poduzetničke prilike kao jedan od početnih izračuna je plan prihoda. Istraživanjem Stanković (2017) planirana je struktura i vrijednost prihoda u proizvodnji kamilice (Tablica 1.).

Tablica 1. Planirana struktura prihoda u proizvodnji kamilice

Table 1 Planning income structure in chamomile production

\begin{tabular}{clccc}
\hline Red. broj/No. & Elementi/Elements & Količina/Quantity $(\mathrm{kg})$ & $\begin{array}{c}\text { Cijena/Price } \\
\left(\mathrm{kn} \mathrm{kg}^{-1}\right)\end{array}$ & Vrijednost/Value (kn) \\
\hline 1. & $\begin{array}{l}\text { Prodaja na veliko/ } \\
\text { Wholesale }\end{array}$ & 800 & 12,00 & $9.600,00$ \\
\hline 2. & $\begin{array}{l}\text { Poticaji (ha)/ } \\
\text { Support (ha) }\end{array}$ & 1 & $2.100,00$ & $2.100,00$ \\
\hline & Ukupno/Total & & $11.700,00$ \\
\hline
\end{tabular}

Izvor/Source: Autori/authors 
Prihodi se ostvaruju prodajom suhog cvijeta kamilice na veliko, iako su mogući ostali oblici prodaje kao prodaja na tržnici i slično. Ostvareni prinos suhog cvijeta kamilice na jednome hektaru u jednoj godini iznosi 800 kilograma, a prodaje se po cijeni $12 \mathrm{kn} \mathrm{kg}^{-1}$ te se postiže prihod u vrijednosti $9.600,00$ kuna. Osim prihoda osnovne proizvodnje, potrebno je uračunati i osnovno plaćanje, odnosno poticaje u iznosu $2.100,00 \mathrm{kn} \mathrm{ha}^{-1}$. Ukupno prihod iznosi $11.700,00$ kuna.

Nakon proračuna prihoda, poduzetnici analiziraju troškove kao vrijednosni izraz ulaganja osnovnih elemenata u proizvodnji, koji nastaju radi stvaranja novih učinaka i stjecanja dobiti. Prema Karić (2002) u troškove se ubrajaju tekuća ulaganja elemenata proizvodnje koja nastaju u poslovanju gospodarskih subjekata, a koja su uvijek izražena u novcu. Troškovi su najvažniji dio rashoda čiji se konačan iznos utvrđuje na kraju poslovne godine. Ukupni se troškovi stavljaju u odnos prema ostvarenim godišnjim prihodima radi utvrđivanja financijskog rezultata proizvodnje. Struktura udjela pojedinih vrsta troškova u proizvodnji kamilice prikazana je Grafikonom 1.

\author{
Sjeme/Seed \\ Rad ljudi/Labour \\ Zakup zemljišta/Land rent \\ Opći troškovi \\ proizvodnje/Overheads \\ Rad sušare/Drier \\ Mineralno gnojivo/Mineral \\ fertilizer \\ Rad strojeva/Mechanization
}

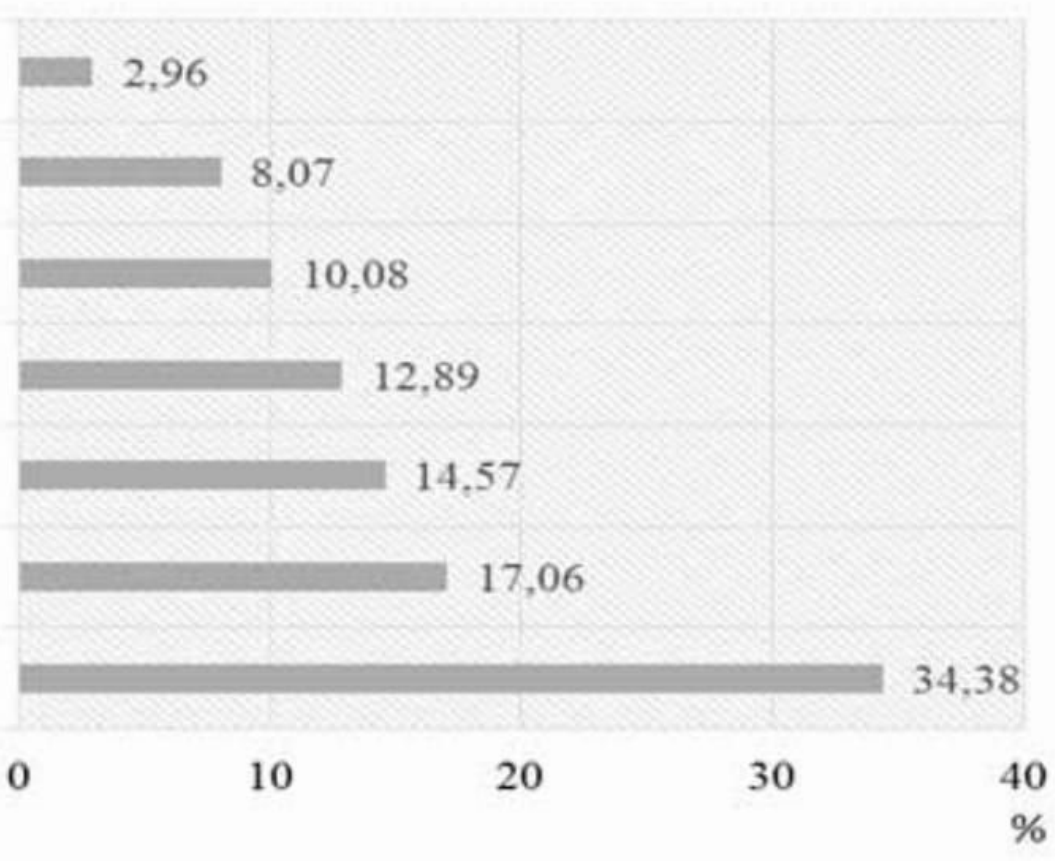

$\%$

Grafikon 1. Struktura troškova u proizvodnji kamilice

Graph 1 Cost structure in chamomile production Izvor/Source: Autori/authors

U proizvodnji kamilice planirana je nabava $12 \mathrm{~kg}$ sjemena po cijeni $22 \mathrm{kn} / \mathrm{kg}$ što čini $2,96 \%$ od ukupnih troškova. Troškovi mineralnih gnojiva čine $17,06 \%$ od ukupnih troškova. Troškovi unajmljene mehanizacije, traktora i kombajna čine $34,38 \%$ od ukupnih troškova. Rad sušare iznosi 14,57 \% od ukupnih troškova. Trošak rada ljudi čini 8,07 \% od ukupnih troškova, što je za $3 \%$ više nego u ostalim ratarskim kulturama. Zakup zemljišta čini 10,08 \% od ukupnih troškova. Opći troškovi proizvodnje čine 12,88 \% od ukupnih troškova proizvodnje kamilice.

Temeljem proračuna prihoda i troškova načinjena je kalkulacija proizvodnje kamilice na jednom hektaru u razdoblju od jedne godine. Iz Tablice 2. je vidljivo kako se proizvodnjom kamilice ostvaruje dobit, odnosno pozitivni financijski rezultat. 
Tablica 2. Planska kalkulacija proizvodnje kamilice

Table 2 Planning calculation of chamomile production

\begin{tabular}{|c|c|c|c|c|c|}
\hline $\begin{array}{l}\text { Red. } \\
\text { broj } \\
\text { (No.) }\end{array}$ & $\begin{array}{l}\text { Opis/ } \\
\text { Description }\end{array}$ & $\begin{array}{l}\text { Jed. mjere/ } \\
\text { Measure unit }\end{array}$ & $\begin{array}{c}\text { Količina/ } \\
\text { Quantity (ha) }\end{array}$ & $\begin{array}{l}\text { Cijena/ } \\
\text { Price }(k n)\end{array}$ & $\begin{array}{l}\text { Vrijednost/ } \\
\text { Value }\left(\mathrm{kn} \mathrm{ha}^{-1}\right)\end{array}$ \\
\hline & PRIHODI/REVENUES & & & & \\
\hline 1. & $\begin{array}{l}\text { Suhi cvijet kamilice/ Dry } \\
\text { chamomile flower }\end{array}$ & $\mathrm{kg}$ & 800 & 12,00 & $9.600,00$ \\
\hline 2. & Poticaji/Support & $\mathrm{kn}$ & & & $2.100,00$ \\
\hline \multirow[t]{2}{*}{ I } & UKUPNO PRIHODI/TOTAL RE & & & & $11.700,00$ \\
\hline & TROŠKOVI/COSTS & & & & \\
\hline 1. & Sjeme/Seed & $\mathrm{kg}$ & 12 & 22,00 & 264,00 \\
\hline \multirow[t]{4}{*}{2.} & $\begin{array}{l}\text { Mineralno gnojivo/ } \\
\text { Mineral fertilizer }\end{array}$ & $\mathrm{kn}$ & & & $1.523,00$ \\
\hline & NPK 15:15:15 & $\mathrm{kg}$ & 150 & 3,90 & 585,00 \\
\hline & NPK 7:20:30 & $\mathrm{kg}$ & 150 & 4,90 & 735,00 \\
\hline & KAN & $\mathrm{kg}$ & 70 & 2,90 & 203,00 \\
\hline \multirow[t]{3}{*}{3.} & Rad strojeva/Mechanization & & & & $3.068,00$ \\
\hline & Traktor/Tractor & sat & 16 & 148,00 & $2.368,00$ \\
\hline & Kombajn/Harvester & sat & 3 & 233,33 & 700,00 \\
\hline 4. & Rad sušare/Drier & $\mathrm{t}$ & 0,80 & $1.625,00$ & $1.300,00$ \\
\hline 5. & Rad ljudi/Labour & sat & 30 & 24,00 & 720,00 \\
\hline 6. & Zakup zemljišta/Land rent & ha & & & 900,00 \\
\hline 7. & Opći troškovi/Overheads & $\mathrm{kn}$ & & & $1.150,00$ \\
\hline ॥ & UKUPNO TROŠKOVI/TOTAL & & & & $8.925,00$ \\
\hline III & FINANCIJSKI REZULTAT/ FIN & RESULT (I - II) & & & $2.775,00$ \\
\hline IV & PROIZVODNA CIJENA/ PRO & PRICE $\left(\mathrm{kn} \mathrm{kg}^{-1}\right)$ & & & 11,16 \\
\hline
\end{tabular}

Izvor/Source: Autori/authors

Proizvodna cijena je zbroj troškova koji su nastali u procesu proizvodnje po jedinici količine dobivenih proizvoda. Ona se izračunava tako da se ukupni troškovi podjele količinom dobivenih proizvoda. Troškovi po kilogramu kamilice iznose 11,16 kn, stoga tržišna cijena istog proizvoda treba biti veća od navedene cijene, kako bi proizvodnja bila ekonomski opravdana. Važno je naglasiti vrijednost poticaja u iznosu od 2.100,00 kn u proizvodnji kamilice. Kada bi izostala ova stavka u proračunu prihoda, proizvodna cijena bila bi svega $7 \%$ viša od otkupne cijene što je neprihvatljivo za proizvođače.

Na dinamičnom tržištu moguće je očekivati variranje cijene suhog cvijeta kamilice između $9,00 \mathrm{kn} \mathrm{kg}^{-1}$ i $15,00 \mathrm{kn} \mathrm{kg}^{-1}$. Primjenom senzitivne analize uočavaju se promjene financijskog rezultata koje nastaju pod utjecajem osciliranja otkupnih cijene kamilice, što je prikazano u Tablici 3. 
Tablica 3. Utjecaj promjena otkupnih cijena na financijski rezultat proizvodnje kamilice

Table 3 Influence of buying-in price changes on the financial result in chamomile production

\begin{tabular}{cccc}
\hline $\begin{array}{c}\text { Dohodak/ } \\
\text { Income }\end{array}$ & $\begin{array}{c}\text { Jedinična cijena/ } \\
\text { Unit price }(\mathrm{kn})\end{array}$ & $\begin{array}{c}\text { Bez osnovnog plaćanja/ } \\
\text { Without basic payment }\left(\mathrm{kn} \mathrm{ha}{ }^{-1}\right)\end{array}$ & $\begin{array}{c}\text { Uključeno osnovno plaćanje/ } \\
\text { Basic payment included (kn ha-1) }\end{array}$ \\
\hline $\begin{array}{c}\text { Cijena niža/ } \\
\text { Lower price }\end{array}$ & 9,00 & $-1.725,00$ & 375,00 \\
\hline $\begin{array}{c}\text { Cijena srednja/ } \\
\text { Medium price }\end{array}$ & 12,00 & 675,00 & $2.775,00$ \\
\hline $\begin{array}{c}\text { Cijena viša/ } \\
\text { Higher price }\end{array}$ & 15,00 & $3.075,00$ & $5.175,00$ \\
\hline
\end{tabular}

Izvor/Source: Autori/authors

U slučaju niže otkupne cijene bez osnovnog plaćanja (poticaja), proizvodnja kamilice nije isplativa te se ostvaruje gubitak u iznosu $1.725,00$ kn. Izračun koeficijenta ekonomičnosti tehnološkog procesa uzgoja kamilice se izračunava tako da se ukupni prihodi stave u odnos s ukupnim troškovima. Koeficijent ekonomičnosti iznosi 1,31 što znači da je proizvodnja kamilice ekonomična.

Ep = ukupni prihodi (kn) / ukupni troškovi (kn); 11.700,00 / 8.925,00 =1,31

Uloženi ljudski rad se može iskazati u različitim mjernim jedinicama: satima, danima, tjednima i mjesecima. Radi lakšeg izračuna u proizvodnji kamilice koristi se mjerna jedinica u satima. Proizvođač kamilice koji unajmljuje sezonske radnike, trošak rada ( $\mathrm{Tr}$ ) utvrđuje množenjem količine uloženog rada s cijenom u kunama. Uloženi rad u proizvodnji kamilice po hektaru je 30 sati, a cijena takvoga rada iznosi 24 kn po satu, dakle ukupni trošak rada iznosi 720 kn.

$\mathrm{Tr}=$ količina utrošenog rada (h) x cijena rada (kn); $30 \times 24=720$ kn

Proizvodnost rada pokazatelj je odnosa između količine proizvedenih proizvoda i radnog vremena koje je potrebno za njegovu proizvodnju. Trošak plaće u proizvodnji kamilice iznosi $8,07 \%$ ukupnih troškova. Proizvodnost rada je izračunata se na dva načina:

$\mathrm{Pr}_{1}=$ količina proizvedenih učinaka $(\mathrm{kg}) /$ količina utrošenog rada $(\mathrm{h}) 800 / 30=26,67 \mathrm{~kg} \mathrm{~h}^{-1}$

Proizvodnost rada iznosi $26,67 \mathrm{~kg}$ suhog cvijeta kamilice po satu.

$\mathrm{Pr}_{2}=$ količina utrošenog rada $(\mathrm{h}) /$ količina proizvedenih učinaka $(\mathrm{t})=30 / 0,8=37,5 \mathrm{~h} \mathrm{t}^{-1}$

Potrebno je 37,5 sati rada za proizvodnju tone suhog cvijeta kamilice.

Rentabilnost je izraz učinkovitosti ukupno uloženih sredstava ili kapitala u određenu proizvodnju. Izražava se stopom rentabilnosti i to kao rentabilnost proizvodnje i rentabilnost kapitala uloženog u proizvodnju (Ranogajec, 2009). Rentabilnost proizvodnje izračunata je stavljanjem u odnos ostvarene dobiti i ukupnog prihoda, na sljedeći način:

$\mathrm{R}_{1}=$ dobit $(\mathrm{kn}) /$ ukupni prihodi $(\mathrm{kn}) \times 100=2.775,00 / 11.700,00 \times 100=23,72 \%$

Stopa rentabilnosti proizvodnje pokazuje koliko se na svakih 100 kuna ukupnog prihoda ostvaruje dobiti. U proizvodnji kamilice ona iznosi $23,72 \%$.

Rentabilnost uloženih sredstava je izraz prinosa na investirani kapital. Njime se mjeri uspješnost poduzetnika u korištenju kapitala. Cilj je ulaganja kapitala stvaranje dobiti, a poduzetnik je odgovoran za uspješnost njegova korištenja (Karić, 2002).

Rentabilnost uloženih sredstava se izračunava kao odnos između ostvarene dobiti i ukupnih troškova, na sljedeći način:

$\mathrm{R}_{2}=$ dobit (kn) / ukupni troškovi (kn) x $100=2.775,00 / 8.925,00 \times 100=31,09 \%$ 
Po drugom izračunu, rentabilnost ukupno uloženih sredstava iznosi 31,09\%, što znači da na svakih 100 kuna troškova poduzetnik proizvodnjom kamilice ostvaruje 31,09 kuna dobiti, što proizvodnju čini profitabilnom.

Rezultati provedenih ekonomskih analitičkih postupaka potvrđuju kako je proizvodnja kamilice ekonomski opravdana. Na jedinici površine (ha) moguće je ostvariti pozitivan financijski rezultat od 2.775 kuna te ekonomski učinkovitu $(1,31)$ i rentabilnu $(23,72 \%)$ proizvodnju. Budući da je istraživanje provedeno na osnovnoj jedinici površine, odnosno jednom hektaru, realno je pretpostaviti kako bi i ekonomski rezultati uspješnosti s rastom proizvodnih površina bili viši.

\section{Zaključak}

Prema analizama ekonomske opravdanosti proizvodnje kamilice kao poduzetničke prilike utvrđena je ekonomičnost koja se potvrđuje koeficijentom 1,31. Relativno niskim investiranim kapitalom postiže se pozitivni financijski rezultat i profitabilnost 31,09\%, a rentabilnost proizvodnje je $23,72 \%$. Kako bi poduzetnici ostvarili višu razinu dobiti kao pozitivne razlike između prihoda i troškova, poslovne aktivnosti trebaju usmjeriti na povećanje prihoda ili snižavanje troškova. Rast prihoda ostvaruje se povećanjem količine i kvalitete proizvoda, ali i višim prodajnim cijenama suhog cvijeta kamilice. Snižavanje troškova uvijek predstavlja izazov za svakog poduzetnika čije mogućnosti značajno ovise o nabavnim cijenama reprodukcijskog materijala i troškovima rada. Preporuka je, u cilju ekonomske učinkovitosti, djelomično inzistirati na povoljnijim otkupnim cijenama, a dijelom svojim znanjima, iskustvom, sposobnostima i vještinama utjecati na snižavanje dominantnih vrsta troškova u strukturi ukupnih troškova.

\section{Literatura}

Centar za poduzetništvo - CZP (2004) Poduzetnička radna bilježnica. URL: http://www.czposijek.hr/savjetovanje-iinformiranje/ (28.4.2018.)

Deže, J., Kanisek, J., Ranogajec, Lj., Tolušić, Z., Lončarić, R., Zmaić, K., Tolić, S., Sudarić, T., Kralik, I., Turkalj, D., Kristić, J., Crnčan, A. (2008) Agroekonomika, Poduzetništvo u poljoprivredi - značenje, perspektive i otpori. Sveučilišni priručnik. Osijek: Sveučilište J.J. Strossmayera u Osijeku i Osječko-baranjska županija.

Ecofoodtura (2016) Analiza stanja i mogućnosti razvoja ekološke proizvodnje. URL: http://www.ecofoodtura.hr/ images/pdf/publikacije/analizaStanja.pdf (9.5.2018.)

Ekopoduzetnik (2012) Agrotehnika uzgoja kamilice. URL: http://www.ekopoduzetnik.com/tekstovi/agrotehnikauzgoja-kamilice-6452/ (15.5.2018.)

Europlantaže (2015) Berba cvijeta kamilice. URL: http://www.europlantaze.com/index.php/en/eko/96-berba-cvijeta-kamilice (28.4.2018.)

Jurčak, J. (2005) Ekonomika i organizacija proizvodnje u poljoprivredi. Zagreb: Sveučilište u Zagrebu.

Karić, M. (2002) Kalkulacije u poljoprivredi. Osijek: Poljoprivredni fakultet u Osijeku.

Parađiković, N. (2014) Ljekovito i začinsko bilje. Osijek: Sveučilište J.J. Strossmayera.

Petrokemija. URL: https://petrokemija.hr/ (3.5.2018.)

Ranogajec, Lj. (2009) Računovodstvo u poljoprivredi. Osijek: Poljoprivredni fakultet u Osijeku.

Sito, S., Kušec, V., Ivandija M., Ciler, K. Palinić, B., Glogovšek, T. (2015) Strojna berba i sušenje kamilice. Glasnik zaštite bilja, 38 (5), 49-56.

Spider grupa (2018) URL: https://spidergrupa.hr/spider-grupa/ (8.6.2018.)

Stanković, A. (2017) Proizvodnja kamilice kao poduzetnička prilika - tehnologija i ekonomika. Završni rad. Osijek: Poljoprivredni fakultet u Osijeku.

Šilješ, I., Grozdanić, Đ., Grgesina, I. (1992) Poznavanje, uzgoj i prerada ljekovitog bilja. Zagreb: Školska knjiga.

Tolušić, Z. (2011) Tržište i distribucija poljoprivredno - prehrambenih proizvoda, drugo dopunjeno i izmijenjeno izdanje. Osijek: Poljoprivredni fakultet u Osijeku.

Žanić, V. (2000) Poslovni plan poduzetnika. Zagreb: Ministarstvo gospodarstva Republike Hrvatske i Masmedia. 